\title{
Being Outdoors: Lived Experience on the Franklin River
}

Marcus Morse, La Trobe University, Australia

Email:m.morse@latrobe.edu.au

Sean Blenkinsop, Simon Fraser University, Canada

Email: sblenkin@sfu.ca

\section{Abstract}

Being outdoors can provide experiential possibilities not readily available indoors. In this paper we draw on phenomenological research undertaken with participants on 10-day outdoor Franklin River journeys in Tasmania, Australia, to illustrate such possibilities. By exploring multiple aspects and variations of participant lived experience outdoors we focus, in particular, on the potential ontological implications of these experiences. We detail three key findings that emerged from participant descriptions: i) a feeling of humility, ii) being alive to the present, and iii) paradox and living with the irresolvable via anecdotes, experiential structures and quotes. In doing so we highlight and discuss what, we suggest, are profound possibilities for participants' ways of being outdoors with/in this vibrant riverscape.

Keywords: Outdoor, phenomenology, experience, river, paradox

\section{Introduction}

"Phenomenologically speaking - experientially - the contrast between the being of outdoors and the being of indoors could hardly be more pronounced." (Italics in original, Hay, 2015, p. vii)

As Hay (2015) indicates, the phenomenological contrasts that exist between the being of human outdoors and indoors are experientially profound. As the reader will note, Hay is implying that these experiential differences reach beyond just a question of phenomena, for this is not simply a question of encountering forests and rivers vs. buildings and human constructions. Those variances in encounters have ontological implications. Being human changes as a result of our experiences and that is influenced by where, and amongst whom/what, those experiences happen. The prereflective of these encounters reveals a deeper implication to the outside world that we hope to show as lived as we travel with multiple groups down the Franklin River, in South-western Tasmania, Australia. 
In order to consider these lived experiences, we draw on phenomenological research undertaken during a Franklin River journey in December 2017 involving both authors. In addition, we consider these findings in light of data gathered during eight earlier Franklin River journeys (Morse, 2014; 2015). The focus for this paper is to consider the ontological implications of this outside experience, and phenomena, as described by the participants. We do so by highlighting three key findings that emerged from the lived experience of participants: i) a feeling of humility, ii) being alive to the present, and iii) paradox and living with the irresolvable. Each of these key findings is described via anecdotes, experiential structures and participant quotes thereby helping us to explore the ontological potential in each. In this way we consider the prereflective experience of participants outdoors that suggest different ways of being in the moment and in the world.

As with any phenomenological research there are limitations to the generalizations that might be drawn. However, for these groups there is a sense that after 10 days spent on the Franklin River there is an everydayness occurring with regards to the outdoors - an absorption of self to become through immersion in the place.

Participants developed over time a set of living norms for being with each other, on the river, and even with the river. However, there is also a flexing of how individuals position themselves with(in) the world; with regard to their cultural positioning, how they describe their experiences and even how they delineate themselves in space and time. And it is this possibility for disruption to participants' ways of being through immersion in the river world that we highlight.

\section{The Franklin River and Phenomenological Approach}

The choice of the Franklin, a remote-wilderness river, as a setting reflects a desire to maximise opportunities to investigate prereflective experiences as they were vividly lived outdoors. In journeying within that place, we acknowledge the Palawa, traditional owners of the land through which we travelled. The Franklin River sits at the centre of the Franklin-Gordon Wild Rivers National Park, in South-west Tasmania, Australia, and our journey begins on the Collingwood River, a small tributary that emerges from the Cheyne mountain range and then joins the Franklin during our first day of rafting. The river trip is usually a 10-day journey commonly consisting of two rafts, two guides, and around eight participants. The Franklin cuts through the heart of an expansive wilderness area. It begins as a small river with relatively easy white-water sections for the first few days, as it meanders through the upper Franklin. Eventually the passage presents several

difficult white-water sections interspersed with substantial waterfalls through the middle Franklin and Great Ravine. Finally, the last few days involve paddling through a series of quiet flat pools and shingle rapids (Griffiths \& Baxter, 1997). This journey involves enough time spent immersed, figuratively and at times literally, such that participants are able to engage with the surrounding environment in a variety of ways.

A phenomenological approach was adopted for this research because it positions the prereflective in personal experience and shows the descriptive and illuminating underlying elements of lived experience. As van Manen (2014) asserts "phenomenology is an inquiry that involves a dynamic play of showing and hiding - our attempt to be attentive to the primordialities of meaning as we encounter and live with things and 
others in our lived-through experiences and everyday existence" (p. 28). Phenomenology, then, makes use of an individual's firsthand account, the lived experience that can be explored to describe phenomena. However, it is more than just a method aimed at explicating individual experiences; instead "the aim is to use these descriptions as a groundstone from which to discover underlying commonalities that mark the essential core of the phenomenon" (Seamon, 2000, p. 159).

\section{The Study}

In this paper we describe findings from journeys down the Franklin River between 2007 and 2017. Sampling of participants involved a process Patton (2002) describes as "purposeful random sampling" (p. 240), whereby participants were selected based on contexts where the phenomena under investigation had been previously observed, yet randomly in the sense that they were selected prior to any experiences taking place.

The primary findings described here emerged from a recent journey in 2017 that involved 15 participants. Participants on this journey were all experienced outdoor environmental educators who voluntarily chose the experience and were selected because of the nature of the journey, but also because their descriptions might provide an opportunity to add to, and further interrogate, findings from earlier research.

Methods for eliciting lived experience descriptions on this journey included researcher participation, recorded group discussions and individual written responses to creative artefacts. The creative activity involved responding to a series of pinhole photographs generated by participants on the river. Participants received the pinhole images soon after the journey and were asked to choose the images that drew their attention, and then to describe the feelings, emotions, experiences, memories or thoughts that were evoked (Morse et al., 2018). The written responses were then considered alongside the recorded group discussions with a series of anecdotes emerging through this reflective process. The inclusion of creative artefacts alongside linguistic reflections proved to be an effective method in garnering evocative lived experience descriptions (see also, Morse et al., 2020).

In order to provide additional depth to the primary findings we also considered data fragments from earlier phenomenological research involving commercial and recreational journeys down the Franklin River. Data sources from this research included observations, interviews, journals, and written responses to follow-up emails from 32 participants. Individual semi-structured interviews were the primary data source for this research, usually occurring on the last day of the journeys, or as soon after as possible, in order to provide opportunities for the experiences to run their course (Borrie, Roggenbuck, \& Hull, 1998; Dewey, 1934). Interviews were transcribed and coded using emergent themes and concept maps constructed for each individual interview (Miles \& Huberman, 1994; Patton, 2002). In adding to the 2017 anecdote data via quotes ${ }^{1}$ from

\footnotetext{
1 We are understanding anecdote and direct quote as being two different, though overlapping, forms of data presentation. The anecdote, following Van Manen's description (1989; 2014, pp 250-260), is a composite description. It is a pulling together of lived experience descriptions such as interviews, images, recorded discussions, participant writings and personal experience into a seemingly singular example. It is, we think, a composite description that honours context and community. As such, they are not directly attributed to a single participant but speak to the lived experience of the group on that trip and the complexity of phenomenological data reporting. The direct quotations, a more familiar research tool for many, are attributed (pseudonyms) and yet we hope that readers remember they too are incomplete, contextual and interpretationally flexible.
} 
earlier participants (names changed to pseudonyms), we hope to re-confirm, deepen, and complexify previous understandings while offering further exploration of experiential possibilities.

Keeping in mind the phenomenological challenge of returning to the immediacy of the original lived experience (van Manen, 1997; 2014), we acknowledge that descriptions of lived experience must not only be incomplete but are also mediated by personal and social/cultural pre-conceptions. Although the potential impossibility of this task on the surface may appear a hindrance, it also provides the opportunity to search at a deeper level, to not be satisfied wholly with the words or categories used, and to interrogate individual experiences in light of creative responses and collective recollections. In other words, to allow participant descriptions and representations to say more than might originally appear to be said (Merleau-Ponty, 1968) via a process of careful interrogative reflection.

\section{Lived Experience Described}

In the following sections we explore three key thematic findings that describe the structures of meaningful experience for participants: i) a feeling of humility and ii) being alive to the present, and iii) paradox and living in the irreversible. We explore these finding through lived experience description in the form of anecdotes (van Manen, 1989; 2014), discussion of phenomena and direct quotes from previous research, in order to allow the data to say more than might originally have been said - or what in its reflective silence "it means to say" (Merleau-Ponty, 1968, p. 39). In doing so, we pay particular attention to describing the ontological and ways of being outdoors.

Throughout this work, one of the consistent themes that arose was that participants found it difficult to express themselves. Although this may in part have been due to a sense of awe within a wild river environment, we also assert it hints at further ontological implications of participants' lived experience. It was as if experiences that were not easily encapsulated by the metaphors, languages, or even the cultural concepts that were ready-to-hand. There was, it appeared, a disjuncture between their expressive range and that which desired expression. Often, we witnessed participants slowing their speech, struggling to find the right words, self-correcting, and sliding into the more poetic. At times the results were quite beautiful and unusual for the participants' typical means of expression. We work to describe these experiences in each of the findings that, at least in part, defy description via the anecdotes and by moving between individual and collective descriptions of lived experience to reveal the underlying commonalities of the phenomenon. However, we also highlight here the linguistic difficulties because they hint at ontological differences in being outdoors that do not easily conform to the more usual, for our participants, and culturally dominant, indoors ways of being.

\section{Part 1: A Feeling of Humility}

After four fun-filled days on the river the tenor of the group has changed. Anticipation is shaded with deepening caution and frivolity has given way to focus. Last night as we slid into this glassy pool we were greeted by the sound of 
water crashing violently away from us. In the near darkness the melody was ferocious and filled the narrow gorge with its reverberations. Those who know the river better than I noted that the water levels were high, precariously so, and, in the hopes of having them drop a bit, have decided that a rest day was in order.

So I find myself standing here on a massive bus-sized boulder right at the entrance to the rapid known as Corruscades. On my right, an idyllic pool, deep still waters where platypuses live, ferns flourish, and the sun glints diamonds off the breeze riffled surface. And on my left, a cataclysm -- foaming waters slamming their frenzied way through a jumble of boulders all strewn akimbo. The power of it all is overwhelming and I am struck by how insignificant my species is here. This is a place where water moves inexorably to the sea, where stone directs movement, and where the locals (e.g. the platypus, the fern, and the gentle breeze) are better equipped to thrive and survive. Yet oddly, my human limitations are not totally disregarded, my insignificance is not complete, for there is, behind the vigorous roar, a sense of belonging, of being able to move within this place. Somehow, I am part of this larger community. It is not measured in human terms nor is it created to satisfy human needs, but it is accepting of me. (Participant anecdote from 2017 journey)

We use the term humility in this section to reflect a broader notion, revealed in part through the anecdote above, of "an outwardly directed orientation toward a world in which one is "just one part"” (Tangney, 2002, p. 416). In a similar way, many participants described a sense of being diminished within the place - yet diminished in a way that also provided a sense of being part of something larger. There was a particular sense of being overwhelmed by physical landscape, the depth of the ravine, the power and constancy of the river, the sheer magnitude of the rainforest. These descriptions of experience appeared to bring with them a sense that the place existed as an independent entity on-itsown.

Participants reported feelings of diminishment in the face of something larger, humbled by the place, of being less in control or of feeling repositioned within a system. Feelings of humility could, as well, involve a perceived reduction of the human; a sense of being reminded that the place, or the natural world generally could carry on without us. There was an element of incomprehensibility and of shifting baselines, both in terms of describing the grandeur of the place and of positioning oneself in the face of that, but also of being able to describe the profound experience to someone else. Intriguingly there were, as described in the anecdote above, accompanying these discomforts, feelings of being touched by a sense of comfort, even belonging. Participants were taken in to become part of some larger assemblage and they felt both vulnerable and comforted simultaneously.

There were also descriptions that included a perceived sense of self: not only as subject but also as object. In the most recent 2017 trip down the Franklin, for example, one participant talked about witnessing the way birds flying up and down stream would adjust their patterns of flight the instant they noticed us. The sense of being seen, interpreted, objectified, and adjusted to by other-than-humans had implications for understanding oneself and the world around that reminds us of the phenomenological work of Merleau-Ponty (1962, 1968; see also Toadvine, 2007), where in the chiasmic 
encounter one is both visible and invisible, toucher and touched (Merleau-Ponty, 1968 pp. 147-148). There is an intriguing sense here of the individual finding themselves being repositioned, and indeed decentered, with regard to the world around. Throughout these descriptions there are echoes of ontology rumbling in less than explicit ways.

We highlight here, also, the ways in which these feelings of humility echo descriptions by participants from earlier research on the same river. Although a sense of diminishment was described physically, it was also described by those participants temporally and via micro-worlds.

I mean there are little creeks that have just carved their way through solid rock to get to their output, to get to the river, to get out to the sea, they've just gone straight through this rock. It's just the interplay of those forces, I mean you know that over time water wears away rock. And then you just see that, that incredible time scale is all sitting there in front of you in evidence. (Sarah)

But the other thing is these feelings of diminishment and the ego dissolving nature of being on the river, part of which is simply a reaction to the grandeur, not the macro grandeur but also the grandeur of those little micro worlds, they could so easily, it could so easily not be awe inspiring and uplifting, but profoundly threatening too... And when you stop and you look around you, you realise how profoundly unimportant you are to the natural flow of life as it unfolds in there. And I think, so I think that sort of lesson in humility... it makes me profoundly aware of how unimportant I am personally, that my species is not the be all and the end all. It's not the last word in value on the planet. (Richard)

It's a weird concept because you only sort of think-you know, as humans we -I mean, you tend to only - you don't think about that, you know? Something seems to, in some ways, only exist when you're experiencing it and when you're there... there's that idea of the power and the temporal nature of us being there, in the fact that it's continuing all the time. (Jessie)

For many participants the encounter within the Franklin riverscape was quite challenging temporally, with many finding it hard to ignore the perceived length of time it takes to turn boulders into cobbles or carve rock into channels - outdoor time was experienced as measured in millennia, or timescales beyond usual comprehension. And as described in the quote above from Richard, participants often described encountering scale via multiple micro-worlds that often provided a sense of diminishment or smallness rather than the more obvious grand macro landscape.

Such encounters with the Franklin, a river that was perceived as existing on its own, were, at times, humbling and decentring. We suggest this decentring deserves recognition, particularly given our ontological focus. Many participants described the relentless power of the river, as having its own obligations, operating under pressures and constraints that were largely free from human interventions, with some expressing a surprised realization that the river exists as an independent entity, regardless of whether or not humans were there to observe it or not. 
One of the ongoing conversations in environmental education, eco-feminism, and other eco-theorizing has been an active critique of human exceptionalism that is part of a particular cultural orientation. This involves a positioning of human as being the measure of all things. Theories rest on possessing language, or opposable thumbs, or tool use, or souls, or the arts, or reason, etc. and yet the end result tends to be that all other life and non-life gives way in the face of human needs. Yet here, there is a sense of humans feeling diminished and it is somewhat disconcerting. They are in a place that almost actively demands their attention and is quite clearly not a tribute to the wonders of human abilities. One possibility to be considered is that the ontological positioning of human as hierarchically superior, which tends to be confirmed by Hay's "being indoors", is being disrupted, flattened even, and that in fact some of the linguistic and metaphorical challenges participants are encountering is related to cultural norms that don't include the tools to describe what is being felt and experienced outdoors. Plumwood (1999) has long worked on decentring humans in part because she understands anthropocentrism (the positioning of humans at the centre of things) as being deeply problematic.

We not only imperil ourselves through loss of sensitivity but also deprive ourselves of the unique kind of richness and joy the encounter with the morethan-human presences of nature can offer. To realize this potential, we will need to reconceive the human self in more mutualistic terms, as a self-in-relationship with nature, formed not in the drive for mastery and control of the other but in a balance of mutual transformation and negotiation (p. 101).

The moments of being decentred for modern humans are potentially powerful encounters and ones that, as many eco-feminists suggest, might be deeply important to any chance of changing the human/nature dualism and the environmental challenges that appear as a result thereof.

\section{Part 2: Being Alive to the Present}

I am brought back to myself by the sound of a grey fantail - this song is familiar and vibrates within the river space. Sitting close to the river, watching fallen myrtle leaves swirl in and out of rock-pools, the dancing of these leaves draws me into the deliberate movement of the river. Here, the river level rises and falls in pulses as it is thrust from a formidable rapid, Newlands Cascades. The river narrows and the steep smooth wall on the far side is covered in small rounds of white lichen to a point marking the high-water level, some two metres above where I am sitting.

Below on the riverbed I am intrigued by the perfectly round sink holes cut into the rock filled with water-worn pebbles. These wishing well pools are filled with moments of high river time. Pebbles shaped by time and place will continue to be reworked, buried, uncovered and swept along. My self edges outwards watching, listening and sensing the river-feeling into this place. Beneath these overhung cliffs, time slows, and I am drawn into river, sheltered and vulnerable at the same time. (Participant anecdote from 2017 journey) 
Descriptions of being alive to the present involved a quality of interaction with the surrounding environment that was, at its core, intimate. Participants described attending and engaging differently in the surrounding environment; that it seemed to demand and effortlessly hold their attention, sometimes through perceived active intrusions from the place itself. The anecdote above, for example, reveals a sensual attention to elements in the surrounding environment; but also, importantly, of being available to provide attention in that moment. Such attention brings with it perceptions that might not otherwise be readily available. As described in the anecdote, there is a perception of a repositioned self with(in) the world, as one is drawn in and led by the water worn pebbles of the riverbank.

Echoed through the anecdote above, as well, participants often described a sensory/embodied experience involving a feeling of intimacy and vulnerability that included an aesthetic perception of beauty. Such feelings were perceived directly, piercing and intruding into the self. The place, then, could be breathed in, smelled, and felt through the skin, with a sense of intrusion into the self; a weakening of the edges of the self, reaching across the boundaries of skin and being.

Participants also described being enfolded within the place and losing their sense of past and future, a loss of ego, and of being captured by the qualities of the interaction itself - a merging of person, place, and experience. Such an expressed loss of self resembles the reflections of Hay (2008), in observing his own Franklin River experience:

The river holds all of time within its flow... the ancient Gondwana forests reached over me, gathered me into time itself, and my life changed, my scale of things, and my understanding of what is right and what is wrong... I am challenged to know myself; I am challenged to lose myself. Perspectives change. I travel an arc of time that has become no-time. (no page - pamphlet)

Again, this structure of experience is confirmed by previous research in which participants described being able to pay attention to the surrounding environment in an intimate way alongside feelings of being lost within, or losing something of oneself.

And noticing those things, that being what you're turning your attention to, is things like, sunlight on water, or, you know, the mist curling off it in the morning, like actually having the time, and turning your attention, turning your attention to those sorts of things... it felt so good to be able to do that... and really involving yourself with what was going on - where you were. It was about day four or five where I was just totally where I was. And again, it was very much about, a bird flying past or a, you know, leaf falling down, like that, this kind of a sensationbased experience. You're quite, you're really quite, overwhelmingly in it, in how much I felt moved by it. Amazing. (Amy)

To be wowed by something that's extraordinary, and beyond anything you could ever make or do or imagine... I think brings you some sort of awareness of yourself in relation to that. Maybe it works as a reduction of the self or something, which feels healthy perhaps. (Vickie) 
Participants in this way were able to trace a shift away from being in the world in the accustomed way, to being in the world differently. A point in time, a threshold or limen, was passed over whereby participants were in the environment in a very different way. It is educationally intriguing to note that this nascent shift of being required several days. A recognizable transitional period appeared to be needed. While this could be related to several possible factors, including what was happening on the trip on that particular day, it was often recalled as the point in time when a participant's everyday existence shifted from their usual surrounds to the place they were in; when one could become lost, completely within the place, dissolving within the moment.

For participants, their attention appeared to be invited, captured and held more readily by the outdoor natural environments than it might otherwise have been indoors. James (2009), in a phenomenological study, suggests that everyday functional surrounds are not always readily able to hold one's attention compared with natural settings, contending that "merely functional things do not hold the attention; in fact many of them have been specifically designed not to hold the attention" (p. 107), and further that "natural things have not been designed to fulfil any human purpose and so there typically seems to be more to them than can be comprehended in instrumentalist or functionalist terms ... so natural things can invite attention" (p. 108). Merleau-Ponty (1962) similarly observes of our perception in everyday surrounds that, "our perception, in the context of everyday concerns, alights on things sufficiently so to discover in them their familiar presence, but not sufficiently so to disclose the non-human element which lies in them" (p. 322). At the heart of this perceived sense of intrusion was a felt response to a particular something. In other words, a perceived difference in how an active and agential other requests attention, bringing with it implications for how one understands self and is positioned in the world. A sense of being addressed by an other, as Zwicky (2014) describes below:

Ontological attention is a response to particularity: this kingfisher, this lagoon, this slant-wise smoky West Coast rain. It is impossible to pay such attention and to regard that to which one attends as a 'resource'. In perceiving this-ness, we respond to having been addressed. (In fact, we are addressed all the time, but we don't always notice this) (p. 37)

\section{Part 3: Paradox and Living in the Irresolvable}

It is late afternoon on our $5^{\text {th }}$ day on the river and the mood is a bit sombre. It has been a busy day with a lot of big drops in the river and some tricky work to get boats and people through safely. The sky has grown overcast and there is a sense of imminent weather. I feel myself turning inwards away from the gray cold and embracing my tired body. Just then my boat captain whispers "wallaby" and calmly points to the bank. It takes a moment for my eyes and brain to sort through the greens and browns that make up this unfamiliar ecosystem. And then I see it - a small body, my first marsupial. It appears, hunched down, hunkering next to the water, not moving. Immersed in my thoughts and joy I wonder why it appears so unresponsive to us. Everything else we have met along the river has acted in some way upon an encounter. I can't recognize any obvious signs of fear 
for instance. But then, approaching me from somewhere outside my rational mind comes a strong sense of melancholia, I am overwhelmed by a profound sense that this being is sad and is considering me as potential ally and danger simultaneously. The feeling grips me for a moment and then I try to dispel it. I am left shaken by the encounter, by having been assessed and found wanting. "I have never seen a wallaby this deep in the gorge before" our guide continues as we slide downstream and out of reach. "I'm guessing it might have been unwell" and I am shaken again by the memory of our encounter.(Participant anecdote from 2017 journey)

The anecdote above reveals a sense of being the watcher and the watched simultaneously - and of being found somehow wanting in that place. Inherent within many experiences described by participants was a paradox - a vibration of irresolvable lived experience that held within it seemingly contradictory possibilities at the same time. In particular, it was through the most recent 2017 trip that this question of paradox came into a distinct focus. The reasons for this is unclear, possibly the different histories of the wild pedagogy participants, maybe the changing thoughts of the authors, maybe the place asserting itself in different ways, maybe all and more. What is intriguing with regard to the discussion about being, is that for most people this possibility of existing in an irresolvable both/and condition appears as unusual.

These paradoxical descriptions were also highlighted in the recent research through sensual perception pairings (an activity that occurred on the river that was recorded) such as: vulnerability and comfort, sharpness and smoothness, stability and change, continuity and complexity, and wildness and home. Despite the fact that they were oft short lived these paradoxical tensions became available and discernable through the turning over of individual and collective descriptions of experience, and were recalled by participants as particularly meaningful. And it was intriguing that such experiences, as described in the anecdote above, often appeared as fleeting and/or difficult to describe; indeed, many participants appeared eager to move on from such perceptual experience.

Merleau-Ponty (1968) provides an example of being in the world with lived irresolvable difference - characterizing the intertwining of two related yet divergent possibilities of perception as "chiasmic" (pp. 130-155), in the sense that the two possibilities continually cross but never actually meet, providing a combined effect that is potentially profound. Such an experience can be profoundly ontological. The term chiasma reflects an intertwining of two anatomical possibilities (such as the intertwining of optic nerves) and is used by Merleau-Ponty "as a figure for understanding both the paradoxical contact and separation of the intersubjective relation" (cited in Toadvine, 2009, p. 111). Merleau-Ponty (1968) describes the reversibility of such perceptions. For example, our right hand touching an object in the world and at the same time attempting to be touched by our other hand. The perception that our right hand might be the touched potentially heightens, or affects, our experience of the touching of an object in the world. But in some ways the participants, and the anecdote about the wallaby, are extending Merleau-Ponty's discussion. It is not just the human that is actively touching, sensing, or making an object of the other but it is also the wallaby, the birds flying up the river, and even the river itself. Here we are not only always and already in the world as Heidegger (1962) would have it but we are also being made sense of, understood, recognized, and 
responded to. And it is this intriguing paradox (of being seer and seen, toucher and touched, knower and known, subject and object) that appeared to affect participants on the Franklin River so profoundly. We would also suggest that this has ontological implications, particularly for those immersed in an ontology that tends towards resolution whether it be teleological, dialectical, or progressive for paradox at its heart is necessarily unresolvable.

Merleau-Ponty (1968) also argues that the simultaneous realization and chiasmic intertwining of the relatedness (I cannot touch the world without being aware that I might be touched) and divergence (I cannot touch and be touched at the same time) of the two perceptions is at the heart of being in the world. And possibly, given the above, being outdoors in the world. There is a profound and inescapable openness to the world; it intrudes into us and we intrude into it: "the seer and the visible reciprocate one another and we no longer know which sees and which is seen" (p. 139). In some ways, for the participants on these trips they were both of and not of the place. Such experiences reflect a perceptual interaction with an already meaningful natural world; a world of which we are intimately a part of and apart from simultaneously.

As suggested previously, lived experiences involving paradox were difficult to describe. Indeed, participants had difficulty not only in the act of expressing the paradox but in admitting that they were occurring; even seeming to be struggling to keep those experiences from surfacing. We highlight this aspect here because we believe the grasping of words to capture the inexpressible, of being outdoors has ontological implications. The inexpressible or non-verbal component of experience that participants appeared to be grasping at appeared to be relational; hinting at a vital quality of interrelating with(in) the world, not only with human others but with the complexity and diversity of the more-than-human world (Abram, 1996). And it is the sense of interrelating that was part of the paradox of being both separate and part of the world, a questioning of boundaries, an awareness of being addressed by an other and a sense of being vulnerable yet comfortable. Although the primary data from the most recent Franklin journey brought this into sharp relief, it is also available within previous research and we highlight direct quotes below from earlier participants.

So there was this side of being alone in this big environment, as well as feeling connected to all things. Those two feelings aren't mutually exclusive I don't think. I think there's a relationship between them. (Morris)

It was like a moment for pause... I felt extremely empowered by how I felt by being there, and, I was feeling... feeling small... despite your size you can still be, you can still climb that big mountain, you can still go over that big rock, you can still swim in that big river, you can still climb that big tree. Like there's... you can live within it. Yeah, I'm not sure if I'm going to be able to verbalise that. (Beth)

The seeming impossibility of the phenomenological task provides an opportunity for describing the seemingly ineffable, because a part of lived experience will always remain hidden but can also become accessible through it. As we have suggested earlier there is an element of interrogative reflection which involves a "showing and hiding" (van Manen, 2014, p. 28) and allowing the world to say, "in its silence it means to say" 
(Merleau-Ponty 1968, p. 39). Although lived experiences of paradox were difficult to describe - the very attempt to describe them assists with the phenomenological task in a practical sense. As Dienske (1985) suggests:

Noticing the ineffable helps us wonder at the world in which we live; consequently, it assists us in our execution of the phenomenological reduction. Then the awareness re-emerges that our reflective life is situated entirely within the unreflected life, and again we realize that everything verbal has its roots in the non-verbal (p. 8).

Attempts by participants to describe paradox were often fleeting or difficult to hold onto, with some participants appearing to prefer them hidden or overshadowed by more common modern narrative of, for example, human separation from surrounding environments. Through this section we have drawn attention to the experience of irresolvable paradox for participants on the Franklin River journeys, and in doing so we acknowledge both difficulties and opportunities available within phenomenological methods for linguistically grasping the seemingly inexpressible of being outdoors.

\section{Interrelatedness and Being Outdoors}

This research provided an example of the lived experience for groups of participants on 10-day outdoor journeys on the Franklin River. It is not to suggest that other outdoor experiences might be, or aim to be, similar; rather, it provides an example of what is possible in the being of outside - an example we contend which would not be readily available inside. Nor are we suggesting that the participants were in fact enacting a different ontology over the course of being on the Franklin for 10 days. But that maybe they were catching glimpses, shimmers, tiny fumes of what an alternative, more relational, ontology might be like.

Participants within this study described experiences of, with and within nature. It is, perhaps, not surprising that qualities of interrelating within the more-than-human world were brought to the fore in this study, as Toadvine (2009) suggests, "in its effort to describe and understand the nature of experience, phenomenology is inevitably led to investigate the experience of nature and, in general, the relation between experience and nature" (italics in original, p. vii). For many participants paying attention to the morethan-human felt good because there was a sense that the surrounding environment demanded their attention. Within experiences of the outdoors there are qualities of interrelating within the more-than-human that can profoundly influence both perceptions and conceptions of who we are, or might be, in the world.

Finally, our sense of this work has been that the participants in this work are experiencing something surprising to them. Whatever it is, it is difficult to put into language, it is, for some, worrisome to admit, it is wonderful and troublesome at the same time, and it clearly plays with the edges of what they know and, possibly more importantly, how and who they are. At the very least these experiences of travelling down the Franklin River appear to have opened up possibilities for participants that were previously under known by them. At the most, these interactions within the outdoors, these opportunities to encounter an active, vibrant, independent, demanding other, are 
something to be acknowledged, engaged with and made a part of our educational practices - because they can impact who our learners become.

\section{References}

Abram, D. (1996). The spell of the sensuous: Perception and language in a more-thanhuman world. Vintage Books.

Borrie, W. T., Roggenbuck, J. W., \& Hull, R. B. (1998). The problem of verbal reports in recreation research: Review, recommendations, and new directions. Tourism Analysis, 2, 175-183.

Dewey, J. (1934). Art as experience. George Allen and Unwin.

Dienske, I. (1985). Beyond words: On the experience of the ineffable. Phenomenology + Pedagogy, 3(1), 3-19.

Griffiths, P., \& Baxter, B. (1997). The ever varying flood. Prowling Tiger Press.

Hay, P. R. (2008). I'm going on The River, Hobart: 25th anniversary of the Franklin River campaign commemorative pamphlet.

Hay P. R. (2015) Outdoors. Not, therefore, indoors. In M. Robertson, R. Lawrence and G. Heath (Eds.), Experiencing the Outdoors: Enhancing Strategies for Wellbeing (pp. vii-ix). Sense Publishers.

Heidegger, M. (1962). Being and time. Harper.

James, S. P. (2009). The presence of nature: A study in phenomenology and environmental philosophy. Palgrave Macmillan.

Merleau-Ponty, M. (1962). Phenomenology of perception. Routledge and K. Paul.

Merleau-Ponty, M. (1968). The visible and the invisible: Followed by working notes. Northwestern University Press.

Miles, M. B., \& Huberman, A. M. (1994). Qualitative data analysis: An expanded source book. Sage Publications.

Morse, M. (2014). A quality of interrelating: Describing a form of meaningful experience on a wilderness river journey. Journal of Adventure Education and Outdoor Learning, 14(1), 42-55.

Morse, M. (2015). Being alive to the present: Perceiving meaning on a wilderness river journey. Journal of Adventure Education and Outdoor Learning, 15(2), 168-180. 
Morse, M. Jickling, B. \& Morse, P. (2018). Views from a pinhole: Experiments in Wild Pedagogy on the Franklin River. Journal of Outdoor and Environmental Education, 21(3), 255-275.

Morse, M. \& Morse, P. (2020) Representing experience: Creative methods and emergent analysis. In B. Humberstone, \& H. Prince (Eds.), Research Methods in Outdoor Studies (pp. 229-242). Routledge.

Patton, M. Q. (2002). Qualitative research and evaluation methods (3rd ed.). Sage Publications.

Plumwood, V. (1999). Paths beyond human-centeredness. In A. Weston (Eds.) An invitation to environmental philosophy (pp. 69-105). Oxford University Press.

Seamon, D. (2000). A way of seeing people and place: Phenomenology in environment-behavior research. In S. Wapner, J. Demick, T. Yamamoto, \& H. Minami (Eds.), Theoretical perspectives in environment-behavior research (pp. 157-178). Kluwer Academic / Plenum.

Tangney, J. P. (2002). Humility. In C. R. Snyder and S. J. Lopez (Eds.), Handbook of positive psychology (pp. 411-419). University Press.

Toadvine, T. (2009). Merleau-Ponty's philosophy of nature. North Western University Press.

van Manen, M. (1989). By the light of anecdote. Phenomenology + Pedagogy, 7, 232253.

van Manen, M. (1997). Researching lived experience: Human science for an action sensitive pedagogy (2nd ed.). Althouse Press.

van Manen, M. (2014). Phenomenology of practice: Meaning-giving methods in phenomenological research and writing. New York: Left Coast Press.

Zwicky, J. (2014). Imagination and the good life. Common Knowledge, 20(1), 28-45. 